\title{
Cues Speak Louder Than Words: Empirical Evidence from Consumer Market of Pakistan
}

\author{
Anam Javeed ${ }^{1}$, *Muhammad Yar Khan ${ }^{2}$, Asif Khurshid ${ }^{3}$, Uzma Noor ${ }^{4}$ \\ ${ }^{1}$ Department of Management Sciences, University of Wah, GT Road, Wah Cantt, Pakistan \\ ${ }^{2}$ Department of Management Sciences, COMSATS University Islamabad, Wah Campus, Pakistan \\ ${ }^{3}$ Department of Management Sciences, Bahria University Islamabad, Sector E-8, Islamabad, Pakistan \\ ${ }^{4}$ Department of Management Sciences, International Islamic University Islamabad, Pakistan
}

\begin{abstract}
The aim of this study is to probe into the impact of extrinsic packaging cues (brand name, price, country of origin and precautionary label) on the quality perceptions of the consumers when the intrinsic qualities are not experienced yet. Consumer knowledge is used a moderator in the study. The study also aims to investigate the influence of the consumer knowledge as a moderator on the relationship between food packaging cues and perceived product quality. Survey was conducted using mall intercept method $(n=478)$ with a self-administered five point Likert scale questionnaire in Rawalpindi and Islamabad. SPSS and PLS were used for analyzing the data. In order to ensure the internal consistency of the variables Cronbach's alpha was used. Among all the variables which were studied in theoretical framework, precautionary label came out to a strong extrinsic in contributing to the formation of product quality perceptions. Additionally, brand name and Price are also considered as important quality determining extrinsic cues. On the other hand, Country of origin as an extrinsic cue turned out to cast no impact on the quality perceptions in Pakistani consumer market. Among the interaction paths, consumer knowledge held a significant role for brand name and country of origin with perceived product quality. This study comprises of number of research limitations. The mall intercept method was utilized in which sample control is difficult. The data was collected from Rawalpindi and Islamabad which might pose a problem for generalizability. Along with the limitations, this study presents horizon for the future researchers by presenting a model of research which could be extended to other marketing contexts. The research revealed that, the schema of extrinsic packaging cues cast a deep impact on the product quality perceptions. The results imply that practitioners need to embed the extrinsic cues much intelligently as they tend to produce prior to the usage quality perceptions regarding the product. This study puts forth a significant understanding regarding the utility of extrinsic packaging cues in the determination of product quality perceptions. The paper provides insights from Pakistani market.
\end{abstract}

Keywords: Cues, Signaling theory; Perceptions; Perceived Product Quality; Consumer Market; Pakistan

*Corresponding author: Muhammad Yar Khan (e-mail: muhammadyar@ciitwah.edu.pk). 


\section{Introduction}

The modern day concept of consumer behavior revolves around the consumer who is the ultimate authority (Pearce 2016). This viewpoint makes it important for the enterprises to get a deeper comprehension of the consumer perceptions for product differentiation as well as to gain competitive edge (Ravikanth and Rao 2016). The product attributes provide an opportunity to the firms to develop their products as per the needs of consumers and develop product differentiation (Charlebois, Schwab et al. 2016). Advertising cues impact the consumer attitude towards the product quality (Dawar and Parker 1994). The combination of extrinsic and intrinsic cues have been used in the past studies (Draper, Adamson et al. 2011).

Packaging plays a pivotal role in marketing and a role of a silent salesperson to attract customers (ST Wang 2013). The cues extended towards the consumer are of vital importance (Hatch and Roberts 1985, Kim 2008). The cues presented on the food packaging creates an impact on the perceptions of the consumers for instance even small numerical differences presented on the package can positively affect the quality perception (Spence and Velasco 2018) . Carefully designed attractive package not only provides physical protection to the enclosed objects but also provide information to customer (Ghani and Kamal 2010). Cues which attract the consumer can trigger the competitiveness among the products and brands (Bauer, Wilkie et al. 2012). Packaging as the container of the product encompasses attributes such as shape, size, design, color, signs and label (Mugge and Schoormans 2012).

Unlike advertising, where consumers may encounter the advertisements in different places (e.g., on TV at home, on roadside billboards, or on radio while driving), consumers notice product packaging mostly at the point of sales and usually in retail stores (Wigley and Rachel Chiang 2009). The visual cues on packaging are considered to have a prime importance because consumers are often under time pressure and give limited attention when choosing among competing brands. In this regard, the visual packaging cues assist the consumer to take the right decision (ST Wang 2013). Especially with fast moving consumer goods, consumers rely on the food packaging cues when picking a product (Honea and Horsky 2012).

\subsection{Setting Scenario of Pakistani Market}

Increasing number of households and growing trend of urbanization in Pakistan makes it prospective market for the usage of packaged food items (Euromonitor International, 2015). Most of the past studies have taken into account the effect of food packaging cues on the purchase intention and generally reported a positive association (Jhang, Grant et al. 2012). The perceptions of the consumers regarding the products is vital for the organizations (Ergin and Akbay 2014). The necessity of studying perceptions of the consumers based on the food packaging cues in variety of markets has been stressed by various researchers (Qasem, Baharun et al. 2016).

\footnotetext{
*Corresponding author: Muhammad Yar Khan (e-mail: muhammadyar@ ciitwah.edu.pk).
} 
From the practical perspective, the packaged food industry in Pakistan has flourished (Zafar, Hashim et al. 2017). The trend of urbanization is increasing in Pakistan and urban consumers are adapting changing lifestyles as compared to their rural counterparts (Euromonitor International, 2016). Moreover, prior studies focus only on the intention to purchase (Zafar, Hashim et al. 2017). Even though the consumers develop the perceptions regarding the product, but they might not be able to do that without the necessary resources and cues (Machiels and Karnal 2016). Additionally, previous studies do not also completely describe the impact of the packaging cues on the perceived product quality (Roselli, Carlucci et al. 2018). Furthermore, perceived product quality has also been proved to be directly impacted by external cues (Roselli, Carlucci et al. 2018) but there are very limited studies focusing on the effect of brand name (Sharma and Garg 2016), country of origin (Herz and Diamantopoulos 2017), price (Huang, Dawes et al. 2017) and precautionary label on perceived product quality.

\subsection{Problem Identification and Research Questions}

Quality perception of buyers has been a major topic of interest in previous literature (Rahman, Fung et al. 2017). These previous attempts seems to be relatively fragmented and do not consider a comprehensive set of packaging cues to describe the quality perceptions of the end user (Lähteenmäki, Lampila et al. 2010, Kelley, Hyde et al. 2015). It has been argued that even though consumer intends to perform a certain behavior but there is a possibility they might not be able to perform without necessary informational cues (Ajzen 1991). The nature of the consumer varies from market to market and cultural differences play a decisive role in the affective and cognitive choices of consumption (Pedersen, Lonner et al. 2015). Considering the argument of studying the variables and theories in Pakistani cultural context can produce interesting results. Thus, the major problem that this study aims to address is that how the extrinsic product packaging cues of brand name, precautionary label, country of origin and price impact the perceived product quality.

Therefore, this study focuses on answering the following two main research questions.

i. What is the impact of extrinsic cues (brand name, country of origin, price and precautionary labels) on perceived product quality?

ii. How the consumer knowledge does moderates the relationship between extrinsic cues (brand name, country of origin, price and precautionary labels) and product quality perception?

\section{Literature Review}

*Corresponding author: Muhammad Yar Khan (e-mail: muhammadyar@ciitwah.edu.pk). 


\subsection{Brand Name}

Brand name is effective in creating product quality perceptions and it establishes the intentions of buyers towards the products (Rungtrakulchai 2018). It is also a key element for the long term success of relationships (Sharma and Garg 2016). With the brand name, buyers generally have to spend very less time to perceive the quality of the product (Randhawa, Kirca et al. 2017). The stout relationship between brand name and product quality perceptions motivates the frequent buying behavior(Mishra, Singh et al. 2017). It has been argued (Lewis, Grebitus et al. 2016) that relation between the brand name and product quality perception is vital as well complex issue and should be probed closely in various markets. The brand name is a factor that casts an impact on the preferences and quality evaluations of the food (Chovanová, Korshunov et al. 2015). It is also considered as an important packaging cue and serves as a quality determinant (Babcanová, Prajová et al. 2012). For the companies, brands ensure the consumer loyalty and determine future cash flows. Brand name is an asset of the business, which has legal protection cover and cannot be duplicated (Chadwick and Holt 2015). It has been argued that brand name not only influences the quality perceptions but also sways brand purchase (Ismail, Masood et al. 2012). Consuming branded food items provides the user with a sense of prestige.

A significant relationship was reported between the brand name and the willingness to pay (Holt 2002). A cross country examination was conducted where mixed responses were reported (Zeb, Rashid et al. 2011). Few studies reported a direct significant nexus between brand name and social acceptance (Grewal, Ailawadi et al. 2011). Consumers in developing countries are very less brand conscious and they prefer the cue of price over brand name (Shehzad, Ahmad et al. 2014). More recently, it has been reported that consumer evaluates the product of a reliable brand positively (Mascarello, Pinto et al. 2015).

\subsection{Country of Origin}

Internationally, the origin of the product labeling can impact the perceptions of the consumers of every age group (Velčovská and Hadro 2018). It has been shown that country of origin effect varies with the consumers belonging to different countries (Insch and McBride 2004). The country of origin has a positive association with product quality judgments of Pakistani consumers and their buying decisions (Khan and Bamber 2008). The literature on the Pakistani consumers regarding impact of country of origin on quality perception is scarce (Saeed and Aslam 2015). By investigating the extant of relationship of country of origin with the product quality perception along with other product packaging cues would be an important theoretical contribution to literature. Image of the country of origin is associated with the product which develops the perceptions of the consumers (Mørkbak, Christensen et al. 2010). The country image is described as the general perceptions and imagery the consumers form about the particular country or region (Türkekul, Günden et al. 2010). The country of origin cue influences the consumer's evaluation of

*Corresponding author: Muhammad Yar Khan (e-mail: muhammadyar@ciitwah.edu.pk). 
quality about the enclosed product (Thøgersen, Pedersen et al. 2017). The country of origin is the effect of product which describes the extent to which the consumer's product evaluations are being influenced by country image (Lee, Lee et al. 2013).

The country of origin has a direct and significant relationship with the consumer's attitude towards the product and intention to purchase (Hsieh 2004). The country of origin of the product has a direct relationship with the perceived quality and consumer purchase intention (Diamantopoulos and Zeugner-Roth 2010). There exists a direct influence of country of origin on the perceived quality and purchase intentions (Rezvani, Dehkordi et al. 2012). It has been observed that country of origin has a varied level of influence on the quality perceptions of the consumers (Pappu, Quester et al. 2005).

\subsection{Price}

The past findings are mixed and varied, therefore inconclusive. For instance, (Kim, Jin et al. 2009) reported a significant relationship however, (Parguel, Delécolle et al. 2016) reported that price does not always cast an impact on quality perceptions. Price is a salient cue of the product whose importance cannot be denied as it serves a quality cue and buyer perceives the eminence of the product from the price (Bolton, Keh et al. 2010). It has been reported in past investigations that consumers have a prevailing belief that higher quality products are worthy of high prices whereas the less expensive products are lesser in quality (Grunert, Bredahl et al. 2004). Conversely, in other researches, price is found to overridden by other informational cues like brand name and packaging information (Homburg, Koschate et al. 2005). The influence of the price as quality indicator is much more powerful when consumer has less knowledge (Weisstein, Monroe et al. 2013).

The price of the product is a multi- dimensional construct. The consumer perceives the quality of the product and brand image through the price display (Riley, Lomax et al. 2004). In another study perceived higher quality of the product was reported to be an important and significant dimension among the other cues of brand name and store name (Truong, McColl et al. 2009). It has also been investigated that the cue of price measure the quality perceptions (Riley, Lomax et al. 2004). Contrasting evidence has been presented in another study in which it is mentioned that the consumers perceive that they are offered value against the higher price they pay for the product (Fassnacht, Kluge et al. 2012). The brands should keep an optimal price to keep their product sacred as well as increase its purchase (Kapferer 2012). Luxury brands should keep their prices higher to endow the consumer with the luxurious effects of the product (Kapferer 2012). The price level is an empirical variable which can be used to measure the perceptions and attitudes of the consumer towards product (Riley, Lomax et al. 2004).

\subsection{Precautionary Label}

*Corresponding author: Muhammad Yar Khan (e-mail: muhammadyar@ciitwah.edu.pk). 
Precautionary labels are basically the health warnings that address the hypersensitivity issues of the consumers (Chiuve, Fung et al. 2011). Some consumers may be hypersensitive to certain specific ingredients of the product. Ingredients mean the components or elements that make up a certain recipe (Tiozzo, Mari et al. 2017). However, the precautionary labels are not only the source of information to the consumer but also a marketing edge for the companies which display it (Turnbull, Adams et al. 2015). On the basis of the argument of (Turnbull, Adams et al. 2015), it can be derived that the consumers consider the precautionary labels for making the perceptions of quality regarding the packaged food. The finding on this relationship are mix. For instance, few studies find a negative relationship between the precautionary label and quality of food (De Blok, Vlieg-Boerstra et al. 2007). On the other hand, few studies have find a positive relationship between precautionary label and the quality of food (Fox, Voordouw et al. 2009).

\subsection{Consumer Knowledge}

A moderator is construct which impacts the strength of relationship between the predictor variable (independent) and criterion or dependent variable (Baron and Kenny 1986). Moderator has a potential to enhance or reduce the course of nexus between independent and dependent variable. It can even change the relationship between the two constructs in both positive and a negative way (Lindley and Walker 1993). The consumers give particular importance to nutritional facts but the information on the labels may not always communicate the intended message (Wills, Schmidt et al. 2009). The use of prior knowledge has been studied in cognitive literature but the role of prior knowledge in food label usage is less studied.

\subsection{Product Quality Perception}

Product quality perceptions has been a topic of interest in modern times also (Priilaid, Human et al. 2017). The concept of product perceived quality has been defined as "product perceived quality is a unique kind of association created in the mind of consumers which not only impact the brand associations on the minds of consumers but also the profitability of the manufacturer" (Aaker and Joachimsthaler 2000). It has been emphasized that perceived quality is dissimilar to actual quality and comprises of a higher level abstraction (Zeithaml 1988). The determination of consumer perceived quality leads to satisfied consumer (Chaudhary 2014). The overall meanings of the perceived quality common in all the definitions is that "perceived product quality is the abstraction of the overall components of the product's both tangible and intangible" (Nath Sanyal and Datta 2011).

The quality attributes are defines as the tangible or intangible features of the product which cast an impact on the quality perceptions of the consumers (Kupiec and Revell 2001). Each cue itself gives an impression which results in perception formation of the consumers (Dawar and 
Parker 1994). The quality is defined as the characteristics in the product that the consumer is looking for and which is close to the perceived judgments of the consumer (Maynes 1976).

In the marketing literature, the perceived quality is described on the basis of cues that a consumer gets from the retail environment. In order to understand the consumer's expectations about the quality, the manufacturer must learn about the perceptions and evaluations of the consumer (Main 1994). The understanding of perceptions of consumers is not an easy task and is only possible with a proper research (Ergin and Akbay 2014). The consumer uses the cue of brand name and price differently in various product categories (Moslehpour and Le Huyen 2014).

\section{Theoretical Framework and Hypotheses Development}

The research framework provides a foundation of the study with the previous literature and it gives a vivid sense of theoretical phenomena proposed in the study. Figure 1 shows the theoretical framework which is being discussed in the study. All the variables under discussion are shown in the figure of theoretical framework.

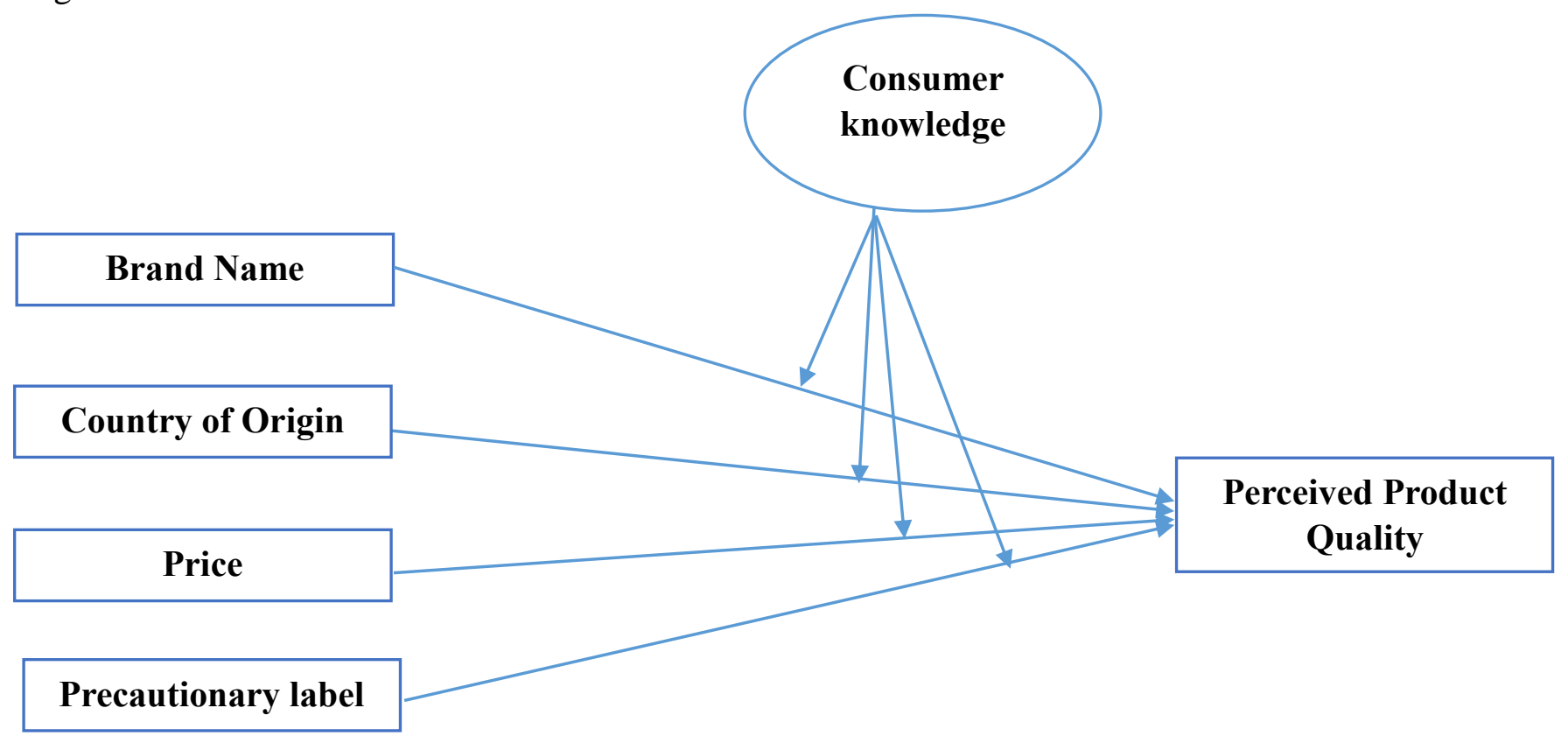

Figure 1 show the theoretical framework which is being discussed in the study

The impact of brand name on the product quality perception, it is disclosed that the brand name effects the product quality perceptions positively (Loken, Ahluwalia et al. 2010). In a study on understanding the impact of brand name awareness confirms that disclosure of proper information has a positive effect on the individual's quality perceptions (Babcanová, Prajová et al. 2012). In another investigation it is revealed that perceptions are influenced significantly by the

*Corresponding author: Muhammad Yar Khan (e-mail: muhammadyar@ciitwah.edu.pk). 
food labels on packaging (Chovanová, Korshunov et al. 2015). There are numerous studies which have found a significant relationship between brand name and product quality perception (Loken, Ahluwalia et al. 2010).

$\mathbf{H}_{1}$ : Brand name has a significant impact on the product quality perception.

The prior studied have verified the relationship between country of origin label and the product quality perceptions (Kalicharan 2014). On the similar grounds, the affiliation has reported significant results in various other studies conducted by (Andéhn and L'Espoir Decosta 2016). The country of origin labels displayed on the food product packages to communicate the source. Various studies have shown the relationship that country of origin labels cast a positive impact on the perceptions of quality in the minds of consumers (Rezvani, Dehkordi et al. 2012). Taking into consideration of the previous studies that have proved the positive effect of country of origin on perceived product quality (Rezvani, Dehkordi et al. 2012, Kalicharan 2014) therefore, this study hypothesizes that:

H2: Country of origin label has a significant impact on product quality perception.

Studies has shown that consumers utilize price as a major quality indicating cue when buying (Kostyra, Reiner et al. 2016). Another investigation proved that price has a significant impact on the perceived product quality (Flach 2016). Numerous studies have confirmed the relationship that the price tag is a strong cue for judging the quality of the product prior to the usage (Mathe-Soulek, Krawczyk et al. 2016). Other studies have also proved that price has a strong impact on the product quality perceptions (Ghasemi, Matta et al. 2016). The cue of price has been recognized to play a substantial role in formation of the product quality perceptions. The cue of price has positive effect on be perceived product quality is also confirmed by (Parguel, Delécolle et al. 2016).

A significant relationship between price and product quality perception has been reported by (Zeithaml 1988). The price is an indicator of quality and instills a sense of prestige (Weisstein, Monroe et al. 2013). Price helps attain a certain level of prestige has been further confirmed by (Truong, McColl et al. 2009). The relationship between price and brand image and found a significant relationship (Kluge and Fassnacht 2014). It is asserted that price display impacts the quality perceptions (Doss and Robinson 2013). Therefore, the third hypothesis for this study can be inferred as:

H3: Price has a significant impact on product perceived quality.

There are many studies pertaining to food labeling which bring ideas and important for the manufacturing industries of food product in the aspect of labeling (Abdul Latiff, Mohamed et al. 2013). According to the survey the consumers have less understanding to label reading and mostly the people with severe allergic reactions like asthma and unconsciousness tend to read the precautionary label more (Cochrane and Ebmeier 2013). Therefore, this study hypothesizes that:

H4: Precautionary labels casts a significant impact on product perceives quality.

*Corresponding author: Muhammad Yar Khan (e-mail: muhammadyar@ciitwah.edu.pk). 
Despite of the theoretical linkage between the extrinsic cues, perceived product quality and role of consumer knowledge as a moderator (Alba and Hutchinson 2000, Veale 2008) not many studies have employed consumer knowledge as a moderator. Hence, this particular study has included the consumer knowledge as moderator between the extrinsic food packaging cues and perceived product quality particularly in Pakistani context. To test the moderating effect of consumer knowledge on the entire image variables one by one, following are the hypotheses to be tested

H5: Consumer knowledge moderates the relationship between brand name and product perceived quality.

Previous studies by various researchers develop a consensus that country of origin as a vital quality indicating cue. Knowledge is based largely on cognitive type learning and experience with the product category via instrumental learning (Alba and Hutchinson 2000). A theoretical nexus has been established by past studies between the consumer knowledge and the extrinsic cues. To understanding the role of consumer knowledge as a moderator between country of origin and perceived product quality it can be hypothesized that

H6: Consumer knowledge moderates the relationship between country of origin and product perceived quality.

In a purchase situation, the ability of interpretation and accurate evaluation of the consumers about extrinsic and intrinsic cues may vary (Kardes, Kim et al. 2001). In most of the situations price is the attribute which is extrinsic to the product and used to assess the quality of the product (Kardes, Kim et al. 2001, Wansink 2004). In order to analyze that how the consumer knowledge moderates the extend of relationship between price and perceived product quality, it can be hypothesized that

H7: Consumer knowledge moderates the relationship between price and product perceived quality.

The precautionary food label as a quality cue by the consumers (Voordouw, CornelisseVermaat et al. 2011). The precautionary labels are comprehensive and communicate uniform and explicit information which communicates the presence of any potential allergen (Voordouw, Cornelisse-Vermaat et al. 2011). A major factor regarding precautionary labels and health claims is that consumers' associate health related perceptions to it (Fulgoni, Keast et al. 2009). As the literature suggests the moderating role of consumer knowledge is rare in analyzing the relation of precautionary label and product perceived quality. Therefore, it is hypothesized that:

H8: Consumer knowledge moderates the relationship between precautionary label and product perceived quality.

*Corresponding author: Muhammad Yar Khan (e-mail: muhammadyar@ ciitwah.edu.pk). 


\section{Methodology}

\subsection{Unit of Analysis}

As the problem statement focused on exploring the perceptions of the consumers towards the food packaging cues, there was a need to gather the responses from the Pakistani consumers. The general consumer in Pakistani market is considered as the unit of analysis for the study. The response from each of the individual is considered as separate data source in the study.

\subsection{Population and Sample of Study}

Sampling is way to overcome the hurdles of collecting data from all of the population which is almost impossible and prohibitive in terms of time and money (Forza 2010). The sample is selected on the basis of their characteristics and properties so that the results could be generalized over the whole population (Uma and Roger 2003). While conducting the investigations, it is practically impossible to collect data from large population, hence the sample is chosen. It has been argued that using an appropriate number of respondents as a sample for your study may save time and other resources (Uma and Roger 2003). The study on the sample produces relatively reliable results by minimizing the errors. The combined population of Rawalpindi and Islamabad is approximately 4.4 million inhabitants. The sample size in the range of 30 to 250 is a small sample size and increasing 500 is considered to be too large (Denscombe 1998). Using the sample of 384 consumers will be appropriate for the study for questionnaire administration (Krejcie and Morgan 1970). The sample has been bifurcated among the cities proportionately as follows in Table 1:

Table 1: City wise Sample Size

\section{City}

Islamabad

Rawalpindi
Calculation

$14300,00 / 44300,00 * 504$

$3000,000 / 44300,00 * 504$

\section{Proportionate Sample Size}

163

341

\subsection{Data Collection Procedure}

This study has been conducted using survey method in shopping malls across the metropolitan cities of Pakistan i.e., Islamabad and Rawalpindi. Data collection for this particular study was carried out for several weeks after pilot testing. A self -administered questionnaire was used to collect the data from the Pakistani consumer market. In this study, the population of interest was general consumer 
visiting the shopping mall. There are a number of shopping malls in Islamabad and Rawalpindi region. However, the largest malls were selected from this region. The respondents were requested to fill up the questionnaire after random starting points on weekdays and weekends during ( 9 am to $3 \mathrm{pm}$ ) and ( $3 \mathrm{pm}$ to $9 \mathrm{pm}$ ). After calculating the sample proportions city wise, from the list of shopping malls, major shopping centers were selected from both of the cities based on the high customer turnout, geographical coverage and popularity. It was not possible to account for the actual number of visitors in the mall. To minimize the bias and to address the time issues as the number of visitors vary considerably across the day, the data collection time was split into two halves of the day (Sudman 1980). Table 2 shows the proportionate sampling time and day wise.

Table 2: Proportionate sample time and day wise

\begin{tabular}{ccccc}
\hline Shopping centre/ City & \multicolumn{2}{c}{$\begin{array}{c}\text { Proportionate Sample } \\
\text { Size on weekdays }\end{array}$} & \multicolumn{2}{c}{$\begin{array}{c}\text { Proportionate Sample } \\
\text { Size on weekends }\end{array}$} \\
\hline & $\mathbf{9}$ a.m- 3 p.m & $\mathbf{3}$ p.m- 9 p.m & $\mathbf{9}$ a.m - 3 p.m & 3 p.m- 9 p.m \\
\hline C M/ Isb & 10 & 12 & 12 & 19 \\
\hline B C/ Isb & 3 & 9 & 16 & 22 \\
\hline K M/Isb & 6 & 16 & 13 & 25 \\
\hline CSD Mall/Rwp & 12 & 22 & 19 & 28 \\
\hline CSD Super Mall/Rwp & 6 & 16 & 19 & 31 \\
\hline G V P Hyper mart/Rwp & 9 & 22 & 25 & 32 \\
\hline R M/Rwp & 13 & 16 & 34 & 37 \\
\hline
\end{tabular}

\subsection{Questionnaire Development}

Independent, dependent and moderating variables were adapted/ adopted from the past studies. Only those questions were selected which has a high Cronbach's alpha. The questionnaire employs two scales namely interval and nominal. Interval scale is used to measure behaviour or personality for example perceptions, attitudes and beliefs. This scale allows researcher to measure the magnitude of differences in preferences. The interval scale has been employed mainly in the section one, two, three, four, five, six, seven and eight to collect the data on the impact of food packaging cues on food quality perceptions. Nominal scale has been employed in section nine to categorize the respondents. This particular study uses Likert scale to measure the responses since this scale is widely used in various areas such as marketing and behavioural sciences. Likert scale measures someone's attitude by measuring the extent to which they agree or disagree with a particular question or statement (Matell and Jacoby 1971). This scale is basically constructed on five response levels or seven response levels. Employing the five point Likert scale is as good as any other (De Winter and Dodou 2010). Five point Likert scale has been chosen to reduce any confusion to the participants and to ensure uniformity among items. Table 3 shows the items of the instrument used in the survey to collect data.

*Corresponding author: Muhammad Yar Khan (e-mail: muhammadyar@ ciitwah.edu.pk). 
Table 3: Items of the Instrument

\begin{tabular}{|c|c|c|}
\hline Code & Survey items/ alpha & Source \\
\hline BN1 & Popular brand name can describe the quality of the product. & \\
\hline BN2 & The branded food product makes me want to buy it. & $\begin{array}{l}\text { (Jamal and Shariffudin., } \\
\text { 2015) }\end{array}$ \\
\hline BN3 & I enjoy eating branded foods. & \\
\hline BN4 & The branded food product has an acceptable standard of quality. & \\
\hline BN5 & The branded food product has a consistent quality. & \\
\hline COO1 & $\begin{array}{l}\text { Country of origin label promotes the positive image of the source } \\
\text { country. }\end{array}$ & \\
\hline $\mathrm{COO2}$ & I am concerned about the country of origin of the food product. & \\
\hline COO3 & $\begin{array}{l}\text { When purchasing the food product, I believe that Country of Origin } \\
\text { label will determine sophistication and quality. }\end{array}$ & (Qasem et al.,2016) \\
\hline COO4 & $\begin{array}{l}\text { To make sure what I buy is high in quality, I seek for the source } \\
\text { country label. }\end{array}$ & \\
\hline PR1 & Higher quality is the consequence of higher price. & (Wang, 2013 ) \\
\hline PR2 & Packaged food items have an acceptable sale price. & \\
\hline PR3 & Packaged food items offer value for money. & (Jamal \& Sharifudin., 2015) \\
\hline PR4 & Packaged food items have a good quality for the price paid. & \\
\hline PR5 & I check the price while shopping for the packaged food. & (Gracia \& Majistris, 2016) \\
\hline PL1 & $\begin{array}{l}\text { Precautionary Label is the source of information regarding potential } \\
\text { allergens. }\end{array}$ & (Ambali \& Bakar, 2014) \\
\hline PL2 & I read the Precautionary Label when I buy food package. & (Louriero et al., 2006) \\
\hline PL3 & $\begin{array}{l}\text { Product with Precautionary Label with high risk of inducing an allergic } \\
\text { reaction is higher in quality. }\end{array}$ & (DunnGalvin et al., 2015) \\
\hline PL4 & $\begin{array}{l}\text { Product with Precautionary Label with low or no risk of inducing any } \\
\text { allergic reaction is higher in quality. }\end{array}$ & \\
\hline PL5 & $\begin{array}{l}\text { There is an increased use of Precautionary Label in packaged food } \\
\text { industry. }\end{array}$ & \\
\hline CK1 & I feel confident about my knowledge of packaged food products. & Veale (2008) \\
\hline CK2 & I feel I know how to judge the quality of packaged food products. & \\
\hline
\end{tabular}

*Corresponding author: Muhammad Yar Khan (e-mail: muhammadyar@ciitwah.edu.pk). 


\begin{tabular}{|c|c|c|}
\hline Code & Survey items/ alpha & Source \\
\hline CK3 & I do not feel very knowledgeable about packaged food items. & \\
\hline CK4 & $\begin{array}{l}\text { Among my circle of friends, I'm one of the 'experts' on packaged } \\
\text { food products. }\end{array}$ & \\
\hline CK5 & $\begin{array}{l}\text { Knowledgeable consumers use packaging cues for perceiving the } \\
\text { quality. }\end{array}$ & \\
\hline PQ1 & The nutrition information on food labels is useful to me. & (Wang, 2013) \\
\hline PQ2 & $\begin{array}{l}\text { I feel confident that I know how to use food labels to choose a } \\
\text { healthy diet. }\end{array}$ & \\
\hline PQ3 & I read food labels because good health is important to me. & \\
\hline PQ4 & Reading labels makes it easier to choose foods. & \\
\hline PQ5 & $\begin{array}{l}\text { Sometimes I try new foods because of the information on the food } \\
\text { label. }\end{array}$ & \\
\hline
\end{tabular}

\section{Analysis and Discussion}

\subsection{Partial Least Square (PLS-SEM) Approach}

This particular study implants structural equation modelling (SEM) for hypothesis testing. Tests for normality such as skewness, kurtosis and Kolmogorov-Smirnov are not required for using smart PLS. It is free of any kind of limiting constraints which makes it a good choice for data analysis and hypothesis testing. Factor analysis and path analysis, both approaches can be used in structural equation modelling. SEM being a unification of both the approaches, concurrently examines both the facets of the model which are measurement model and structural model. Measurement model is measured conventionally by factor analysis and structural model is estimated through path analysis.

\subsection{Reliability}

Measuring the internal consistency of the items ascertained for the construct is termed as reliability (Hair, Ringle et al. 2011). The Cronbach's alpha coefficient primarily tends to reflect the items 'consistency and as such, higher Cronbach's alpha values indicate higher consistencies which further reflect a higher tendency to measure the intended construct. Convergent validity illustrates the homogeneity of the scale whereas discriminant validity refers to the heterogeneity of the constructs, that is, the extent to which the measure is unique from other measures (Malhotra and 
Galletta 1999). Is this particular study in terms of validity we expect to see an item related to the items which measure the same construct (convergent validity) and on the other hand different from the items which measure different constructs (discriminant validity. Table 4 shows reliability test values.

Table 4: Reliability Test

\begin{tabular}{|c|c|c|c|c|c|}
\hline Serial No & Construct & $\begin{array}{l}\text { Composite } \\
\text { Reliability }\end{array}$ & Cronbach's Alpha & No .of Items & Items \\
\hline 1. & Brand Name & 0.861 & 0.836 & 5 & $\begin{array}{l}\text { BN1 } \\
\text { BN2 } \\
\text { BN3 } \\
\text { BN4 } \\
\text { BN5 }\end{array}$ \\
\hline 2. & $\begin{array}{l}\text { Country of } \\
\text { Origin }\end{array}$ & 0.867 & 0.806 & 4 & $\begin{array}{l}\mathrm{COO} 1 \\
\mathrm{COO} 2 \\
\mathrm{COO} 3 \\
\mathrm{COO} 4\end{array}$ \\
\hline 3. & Price & 0.861 & 0.801 & 5 & $\begin{array}{l}\text { PR1 } \\
\text { PR2 } \\
\text { PR3 } \\
\text { PR4 } \\
\text { PR5 }\end{array}$ \\
\hline 4. & $\begin{array}{l}\text { Precautionary } \\
\text { label }\end{array}$ & 0.876 & 0.849 & 5 & $\begin{array}{l}\text { PL1 } \\
\text { PL2 } \\
\text { PL3 } \\
\text { PL4 } \\
\text { PL5 }\end{array}$ \\
\hline 5. & $\begin{array}{l}\text { Perceived } \\
\text { quality }\end{array}$ & 0.907 & 0.851 & 5 & $\begin{array}{l}\text { PQ1 } \\
\text { PQ2 } \\
\text { PQ3 } \\
\text { PQ4 } \\
\text { PQ5 }\end{array}$ \\
\hline 6. & $\begin{array}{l}\text { Consumer } \\
\text { knowledge }\end{array}$ & 0.920 & 0.916 & 5 & $\begin{array}{l}\text { CK1 } \\
\text { CK2 } \\
\text { CK3 } \\
\text { CK4 } \\
\text { CK5 }\end{array}$ \\
\hline
\end{tabular}

\subsection{Validity Test}

Even though the instrument possess reliability but they do not necessarily imply goodness of the measurements (Uma and Roger 2003). The instrument might lack the aspect of validity. The two basic measures of validity are content validity and construct validity. The judgmental assessment regarding the questionnaire and its constructs by the experts is called the content validity. Construct validity is performed to ascertain that a test is evaluating the construct it was

*Corresponding author: Muhammad Yar Khan (e-mail: muhammadyar@ciitwah.edu.pk). 
actually supposed to (Brown 1983). To ensure the overall validity, construct validity is deemed necessary. Factor analysis was performed to ensure the construct validity. Sampling adequacy was measured by using KMO (Kaisee-Mayer-Olkin) value. KMO index is utilized to make contrast among the enormities of observed correlation coefficient and partial correlation coefficient (Kaiser 1974). According to Kaiser (1974), the KMO values should not be less than 0.5. According to the generally accepted criteria of the statisticians, the variables with Eigen values more than 1.00 are suitable for analysis. It is evident in Table 5 that all the Eigen values are more than 1.00 which shows that all the variables are fit for analysis. The values of the variance also range from 63.445 to 70.559 and Bartlett significance values evidently explain that variables are deemed fit for the analysis. Table 5 shows the factor analysis

Table 5: Factor Analysis

\begin{tabular}{|c|c|c|c|c|c|c|c|c|c|}
\hline Construct & $\begin{array}{l}\text { No. of } \\
\text { Items }\end{array}$ & Items & $\begin{array}{l}\text { Factor } \\
\text { Loading }\end{array}$ & KMO & $\begin{array}{c}\text { Barttle } \\
\text { t Sig. }\end{array}$ & $\begin{array}{l}\text { Eigene } \\
\text { Value }\end{array}$ & $\begin{array}{c}\% \\
\text { variance }\end{array}$ & $\begin{array}{c}\text { Cronbach } \\
\text { Alpha }\end{array}$ & $\begin{array}{l}\text { Deleted } \\
\text { Items }\end{array}$ \\
\hline Brand Name & 5 & $\begin{array}{l}\text { BN1 } \\
\text { BN2 } \\
\text { BN3 } \\
\text { BN4 } \\
\text { BN5 }\end{array}$ & $\begin{array}{l}0.545 \\
0.735 \\
0.745 \\
0.716 \\
0.775\end{array}$ & 0.749 & 0.00 & 1.066 & 70.559 & 0.836 & NIL \\
\hline $\begin{array}{c}\text { Country of } \\
\text { Origin }\end{array}$ & 4 & $\begin{array}{l}\mathrm{COO} 1 \\
\mathrm{COO} 2 \\
\mathrm{COO} 3 \\
\mathrm{COO} 4\end{array}$ & $\begin{array}{l}.527 \\
.753 \\
.740 \\
.518\end{array}$ & 0.768 & 0.00 & 2.538 & 63.445 & 0.806 & NIL \\
\hline Price & 5 & $\begin{array}{l}\text { PR1 } \\
\text { PR2 } \\
\text { PR3 } \\
\text { PR4 } \\
\text { PR5 }\end{array}$ & $\begin{array}{l}.706 \\
.562 \\
.523 \\
.711 \\
.653\end{array}$ & 0.728 & 0.00 & 1.089 & 67.939 & 0.801 & NIL \\
\hline $\begin{array}{c}\text { Precautionary } \\
\text { label }\end{array}$ & 5 & $\begin{array}{l}\text { PL1 } \\
\text { PL2 } \\
\text { PL3 } \\
\text { PL4 } \\
\text { PL5 }\end{array}$ & $\begin{array}{l}0.578 \\
0.683 \\
0.646 \\
0.593 \\
0.769\end{array}$ & 0.734 & 0.00 & 1.042 & 67.623 & 0.849 & NIL \\
\hline $\begin{array}{c}\text { Perceived } \\
\text { quality }\end{array}$ & 5 & $\begin{array}{l}\text { PQ1 } \\
\text { PQ2 } \\
\text { PQ3 } \\
\text { PQ4 } \\
\text { PQ5 }\end{array}$ & $\begin{array}{l}0.686 \\
0.712 \\
0.757 \\
0.631 \\
0.620 \\
0.650\end{array}$ & 0.789 & 0.00 & 1.485 & 68.097 & 0.851 & NIL \\
\hline $\begin{array}{l}\text { Consumer } \\
\text { Knowledge }\end{array}$ & 5 & $\begin{array}{l}\text { CK1 } \\
\text { CK2 } \\
\text { CK3 } \\
\text { CK4 } \\
\text { CK5 }\end{array}$ & $\begin{array}{l}0.632 \\
0.574 \\
0.675 \\
0.550\end{array}$ & 0.800 & 0.00 & 5.313 & 59.032 & 0.911 & NIL \\
\hline
\end{tabular}

*Corresponding author: Muhammad Yar Khan (e-mail: muhammadyar@ciitwah.edu.pk). 


\subsection{Respondents Profile}

For a comprehensible discussion of results, it is necessitated to understand the profile of the respondents. Table 6 shows the clear canvas of the profiles of the respondents. Total of 478 respondents were put to analysis.

Table 6: Respondents' Profile

\begin{tabular}{cccc} 
Demography & Indicator & Frequency & Percentage \\
Gender & Male & 193 & 40.4 \\
\hline \multirow{2}{*}{ Education } & Female & 285 & 59.6 \\
& High school & 206 & 43.1 \\
& Bachelor & 167 & 34.9 \\
\hline & & & 24.5 \\
Age Group & Masters & 71 & 7.1 \\
& Doctorate & 34 & 33.5 \\
& $18-25$ & 160 & 34.9 \\
& $26-33$ & 167 & 24.5 \\
& $34-41$ & 117 & 7.1
\end{tabular}

The results exhibit that $59.6 \%$ of respondents who participated in the survey were female however, 40.4 of the participants were males. Furthermore, $43.1 \%$ of the participants of the study possessed high school qualification and $34.5 \%$ possess bachelors. Academic qualification of masters was acquired by $24.5 \%$ of the respondents and doctorate was held by $7.1 \%$ of the consumers. Thereafter, $33.5 \%$ of the respondents fall into the age bracket of 18-25 years. Maximum respondents $34.9 \%$ were found to be in the age limits of 26-33 years. Rest of $24.5 \%$ of the consumers were in age limit of 34-41 years and 7.1 of the remaining consumers were 41 years and above.

\subsection{Response Rate}

Out of 504 distributed questionnaires all of them were received back on the spot by the researcher, attaining the goal of $100 \%$ response rate however, 478 questionnaires were rendered usable out of 504 distributed questionnaires hence achieving a valid response rate of $95 \%$. As there was direct contact with the respondents there was no issue of questionnaire rejection on the grounds of unreturned questionnaires. However, the researcher came across the issue of consumers' unwillingness to participate in the survey which is considered to be normal in surveys. All the 
questionnaires were observed promptly after being filled by the respondents. Table 7 shows the response rate of the questionnaire distribution.

Table 7: Summary of Response Rate

\begin{tabular}{|c|c|c|c|c|c|c|}
\hline City & Malls & $\begin{array}{l}\text { Populati } \\
\text { on }\end{array}$ & $\begin{array}{l}\text { \%age of } \\
\text { sample }\end{array}$ & $\begin{array}{l}\text { Questionnaire } \\
\text { distributed }\end{array}$ & $\begin{array}{l}\text { No. of } \\
\text { responses }\end{array}$ & $\begin{array}{l}\text { Response } \\
\text { rate }\end{array}$ \\
\hline Islamabad & $\mathrm{C} \mathrm{M}$ & 1700 & $10.5 \%$ & 53 & 53 & $100 \%$ \\
\hline Islamabad & B C & 1600 & $9.9 \%$ & 50 & 50 & $100 \%$ \\
\hline Islamabad & K M & 1900 & $11.8 \%$ & 60 & 60 & $100 \%$ \\
\hline Rawalpindi & $\begin{array}{l}\text { CSD } \\
\text { Mall }\end{array}$ & 2600 & $16.1 \%$ & 81 & 81 & $100 \%$ \\
\hline Rawalpindi & $\begin{array}{l}\text { CSD } \\
\text { Super } \\
\text { Mall }\end{array}$ & 2300 & $14.3 \%$ & 72 & 72 & $100 \%$ \\
\hline Rawalpindi & $\begin{array}{ll}\mathrm{G} \quad \mathrm{V} \quad \mathrm{P} \\
\text { hyper } \\
\text { mart }\end{array}$ & 2800 & $17.4 \%$ & 88 & 88 & $100 \%$ \\
\hline Rawalpindi & $\mathrm{R} \mathrm{M}$ & 3200 & $19.8 \%$ & 100 & 100 & $100 \%$ \\
\hline & & 16100 & $100 \%$ & 504 & 504 & $100 \%$ \\
\hline
\end{tabular}

\subsection{Path coefficient and Significance Test}

The significance level, path coefficients and the t-values are utilized for testing of hypotheses (Hair, Ringle et al. 2011). The path coefficients are standardized beta values. The values of coefficients range from +1 to -1 . The strong positive relationship is signified by the values which are closer to +1 and a strong negative relation is depicted by the values which are closer to negative 1(Henseler, Ringle et al. 2009). When the signs of the path coefficients are opposite to the hypothesized direction, the hypothesis is considered to be not supported. The paths which are empirical supported exhibit the sign which is in line with the hypothesized direction (Hair, Ringle et al. 2013). The researcher initially runs PLS algorithm to obtain the path coefficients and afterwards bootstrapping is done on structural model in order to test the hypotheses. Table 8 shows the path co-efficient and significance levels of the constructs under investigation. 
Table 8: Path co-efficient and significance level

$\begin{array}{cccc}\text { Construct name } & \text { B-values } & \text { T-values } & \text { P-values } \\ \text { Brand name }(\mathbf{B N}) & 0.123 & 2.873 & 0.004 \\ \text { Country of origin }(\mathbf{C O O}) & 0.025 & 0.622 & 0.534 \\ \text { Price }(\mathbf{P R}) & 0.081 & 1.927 & 0.055 \\ \text { Precautionary label }(\mathbf{P L}) & 0.272 & 4.512 & 0.000 \\ \text { BN×CK } & 0.121 & 1.698 & 0.090 \\ \text { COO } \times \mathbf{C K} & -0.130 & 2.134 & 0.033 \\ \mathbf{P R} \times \mathbf{C K} & 0.054 & 1.496 & 0.135 \\ \mathbf{P L} \times \mathbf{C K} & 0.054 & 1.201 & 0.230\end{array}$

\subsection{Hypotheses Testing}

Primarily, the function of algorithm was applied to produce the path coefficients. Furthermore as a next step, bootstrapping is carried out with 500 sample size. The sample size selected while running Smart PLS must be greater than the actual sample size which is a condition recommended by (Hair, Ringle et al. 2013). After determination of goodness of fit of the model, path coefficients are determined. The path coefficients are used in order to inspect the hypothesized relationships. The predictable t-tests are not assessed in PLS (Barclay, Higgins et al. 1995). Non-parametric procedures such as bootstrapping are used for generation of significance of tests. This study utilized bootstrapping technique which is implanted in Smart PLS to check out the statistical significance of the path coefficients. The variable which interacts with the predictor variable to elucidate the criterion variable is called as moderator variable (Baron and Kenny 1986). The interaction takes place when the impact of independent variable on dependent variable fluctuates with level of a third variable known as moderator. In this particular study, consumer knowledge is used as a moderator for the hypothesized relationships. The interaction latent construct has been established using the product indicator approach. Six interaction effects have been created in this study. The interaction latent constructs of Brand name $\times$ Consumer knowledge $(\mathrm{BN} \times \mathrm{CK})$, country of origin $\times$ Consumer knowledge $(\mathrm{COO} \times \mathrm{CK})$, Price $\times$ Consumer knowledge $(\mathrm{PR} \times \mathrm{CK})$, Precautionary label $\times$ Consumer knowledge $(\mathrm{PL} \times \mathrm{CK})$ have been examined using bootstrapping procedure with 500 sample. Table 9 shows the summary of all the main hypotheses.

\footnotetext{
*Corresponding author: Muhammad Yar Khan (e-mail: muhammadyar@ciitwah.edu.pk).
} 
Table 9: Path coefficients of Hypotheses

\begin{tabular}{cccccc}
\hline Hypotheses & Relationships & B-values & T-values & P-values & Decision \\
\hline $\mathbf{H}_{\mathbf{1}}$ & BN-->PQ & 0.123 & 2.910 & 0.004 & Accepted \\
\hline $\mathbf{H}_{\mathbf{2}}$ & COO-->PQ & 0.027 & 0.646 & 0.519 & Rejected \\
\hline $\mathbf{H}_{\mathbf{3}}$ & PR-->PQ & 0.082 & 2.056 & 0.040 & Accepted \\
\hline $\mathbf{H}_{\mathbf{4}}$ & PL-->PQ & 0.272 & 4.620 & 0.000 & Accepted \\
\hline $\mathbf{H}_{5}$ & BN $\times \mathrm{CK}$ & 0.121 & 1.698 & 0.090 & Accepted \\
\hline $\mathbf{H}_{\mathbf{6}}$ & $\mathrm{COO} \times \mathrm{CK}$ & -0.130 & 2.134 & 0.033 & Accepted \\
\hline $\mathbf{H}_{7}$ & PR $\times \mathrm{CK}$ & 0.044 & 0.814 & 0.416 & Rejected \\
\hline $\mathbf{H}_{\mathbf{8}}$ & $\mathrm{PL} \times \mathrm{CK}$ & -0.133 & 1.201 & 0.230 & Rejected \\
\hline
\end{tabular}

The following hypothesized relationships were examined in the study

H1: It has been hypothesized in the study that brand name has a significant impact on consumer's product quality perception. The bootstrapping results also show that brand name casts a significant impact on the product quality perceptions $(\beta=0.123, \mathrm{t}=2.910, \mathrm{p}=0.004)$.

H2: The results $(\beta=0.027, \mathrm{t}=0.646, \mathrm{p}=0.519)$ indicates that no significant relationship exists between country of origin perceived product quality.

H3: Third hypothesis of the study states that price has a positively significant impact on perceived product quality. Bootstrapping results provides support to the hypothesis $(\beta=0.082, t=2.056, p=$ 0.040).

H4: Precautionary labels casts a significant impact on product perceives quality. The results show that $(\beta=0.272, t=4.620, p=0.000)$ precautionary labels and perceived product quality has highly and significantly associated.

H5: As the results reveal that the interaction effect for brand name H7 is supported ( $\beta=0.121 ; \mathrm{t}=$ 1.698; $\mathrm{p}=0.090$ ). The results indicate that high level of consumer knowledge regarding the brand, the better will be the quality perception of consumers regarding the packaged food product.

H6: The hypothesis stated that consumer knowledge moderates the relationship between country of origin and perceived product quality. The bootstrapping results signify that consumer knowledge negatively moderates the relationship of country of origin and perceived product quality $(\beta=-0.130 ; \mathrm{t}=2.134 ; \mathrm{p}=0.033)$.

H7: The next hypothesis of study under discussion is that consumer knowledge moderates the relationship between the price and perceived product quality $(\beta=0.054 ; \mathrm{t}=1.496 ; \mathrm{p}=0.135)$. However, the outcomes reveal that consumer knowledge does not moderate this relationship, hence rejecting the hypothesis.

*Corresponding author: Muhammad Yar Khan (e-mail: muhammadyar@ciitwah.edu.pk). 
H8: The variable of consumer knowledge does not show any significant interaction effect with precautionary label and perceived product quality, hence rejecting the hypothesis that consumer knowledge significantly moderates the relationship of precautionary label and perceived product quality $(\beta=0.054 ; \mathrm{t}=1.201 ; \mathrm{p}=0.230)$.

\section{Discussion}

The first main objective of the study is to determine the impact of extrinsic product packaging cues on perceived product quality. For achieving this objective, first hypothesis is devised. Brand name is taken as an independent variable and perceived product quality is taken as a dependent variable. The first hypothesis is accepted using PLS bootstrapping technique. The prevalence of positive and significant relationship between brand name and perceived product quality can be ascribed to the likelihood that brand name as a packaging element is considered as an essential quality cue. The brand name aids the consumer to develop perceptions regarding the packaged food product. The result of the hypothesis could also be explained like product quality is judged by the consumer prior to the usage by taking into consideration the brand name. This result is in line with outcomes of (Qasem, Baharun et al. 2016) whose findings also reveal that brand name casts positively significant impact on the quality perceptions of the consumers.

The second hypothesis of the study is defined as a positive and significant relation exists between country of origin and brand name was not accepted as shown by the results. The absence of the significant relationship between the variables can be attributed to the fact that country of origin cue is subjugated in the presence of other marketing cues. The results can be otherwise explained that Pakistani consumers are less aware of the country of origin labelling as most of researches are being carried out in European markets. The results corroborate with the findings of (Kalicharan 2014).

The third hypothesis of the study proposes that price impacts the perceived product quality significantly. The hypothesis is accepted. The positively significant relationship possibly emerges from the fact that Pakistani packaged food consumer is becoming health conscious, they expect the value from the product in exchange of money as well as they believe in the genuineness of the product. The results of the study in line with the findings of (Miyazaki, Grewal et al. 2005) who claim that the price of the product is a sheer indicator of quality for the consumers prior to its actual usage.

The subsequent fourth hypothesis states a significant effect of precautionary label on perceived product quality is found to be accepted. The substantial relationship of precautionary label and perceived product quality arises from the likelihood that Pakistani consumers suffering from various kinds of food allergies tend to have an inclination towards the presence of precautionary labels and contemplate the packaged food with this label of good quality in comparison with the products without any such display of information. The results of the study conforms with the outcome of (Zurzolo, Koplin et al. 2013).

\footnotetext{
*Corresponding author: Muhammad Yar Khan (e-mail: muhammadyar@ciitwah.edu.pk).
} 
The fifth hypothesis of the study proposes a significant interaction effect of consumer knowledge on the relationship between brand name and perceived product quality is found to be supported. The observed interaction impact of consumer knowledge reveals that with changing levels of consumer knowledge consumers perceive product quality towards the brand name also changes. The results are in conformance with the findings of (Rao and Monroe 1988) who revealed that brand name has an impact on the perceived product quality whereas prior consumer knowledge moderates this relationship.

The subsequent hypothesis $\mathrm{H}_{6}$ proposes that consumer knowledge moderates the relationship between country of origin and perceived product quality. The hypothesis is seen to be supported by results. The prevalence of moderating effect shows that with the varying levels of consumer knowledge the quality perceptions of consumers formed through country of origin label also fluctuates. The relationship however is being supported with a negative sign, which indicates that increased consumer knowledge results in decreased level of quality perceptions. The results are contrary to the findings of various studies being carried out in European consumer markets. Put differently, the results can be explained that consumers of Pakistan are not well aware of the concept of country of origin so far because of the lack of research as well as the impact of country of origin label is minimal in the presence of other marketing cues (Kalicharan 2014).

The seventh hypothesis asserts that consumer knowledge interacts the relationship between price and perceived product quality. The results indicated that consumer knowledge shows no moderating effect on the relationship. With the fluctuating levels consumer knowledge regarding the price does not lead to any of the fluctuation in the levels of perceived product quality. Alternatively, with the high of low levels of knowledge related to pricing the Pakistani consumer has a tendency to behave correspondingly. The results to some extent correspond to the results of (Veale and Quester 2009) in which it was revealed that consumer knowledge has a very minimal effect as a moderator.

The final hypothesis declares that the relationship between precautionary label and perceived product quality is moderated by consumer knowledge is seen not to be supported. The consumers with high or low level of consumer knowledge tends to behave similarly while forming quality perceptions towards precautionary labels. The findings are in line with the outcomes of (Choi and Choi 2016).

\section{Conclusion}

The findings can be concluded as, overall extrinsic cues possess a significant and positive impact on perceived product quality. Taking into account the outcomes, the marketers are left with a single choice to take into consideration the packaging and labelling as noticeable extrinsic cues. The extrinsic cues whose effect on perceived product quality is the matter of interest for the researcher come out to be effective indictors of quality (pre-trial). As a concluding remark, a need

*Corresponding author: Muhammad Yar Khan (e-mail: muhammadyar@ ciitwah.edu.pk). 
exists on the edge of marketers of Pakistan to recognise these extrinsic cues on the packaged food product as key drivers for quality perception.

\section{Contributions}

This study aims to contribute to the consumer behavior knowledge in several ways.

\subsection{Theoretical Contribution}

From theoretical point of view, this study is significant in following ways. For instance, this study presents a comprehensive model for understanding the consumer quality perceptions formed on the basis of food packaging cues. Limited number of studies has focused on the Pakistani consumer market. It widens the knowledge base by highlighting the relation between the concept of food packaging and product quality perception. Unlike the developed world, there is minimal research work on food packaging cues in developing countries. The marketing all around the world is changing. The attractive packages are becoming a major tool of communication and perception formation. The packaging of food products is also becoming innovative. The food packages have visual representations which the consumers see and respond to. The consumers of the Pakistan are attracted to labeling and are conscious about the quality they perceive from these labels but there is a lack of understanding. As suggested by literature, limited attention has been given in Pakistani market to study consumer perceived quality, hence this study aims to fills the research gap in this regard. This research would contribute to the generalizability of cue utilization theory, total food quality model and cognitive behavioral learning theory. As all these theories have yielded empirical results in western markets which might not be applicable to other countries. This research bridges the gap by providing insight regarding the consumer market of a developing country. This study also contributes to the body of knowledge by testing the applicability of existing theories in an under developed country's market. However, the significance of the investigation is that it offers comprehensive information about the product quality perceptions formed on the basis of extrinsic food packaging cues.

\subsection{Methodological Contribution}

Along with theoretical contributions, this study has made few methodological contributions as well. Firstly, this study employs rigorous systematic random sampling. Mall intercept method is considered to be weak sampling technique. Nevertheless, this study is a footstep ahead in considering very little detail in terms of gate sampling, day and time sampling. By taking into consideration, the minute details increase the factor of randomness which facilitates generalizations. As per the inadequate knowledge of the researcher, this study is among the primary ones in Pakistan. This study also anticipates the upcoming researchers to achieve data from the mall intercept technique

*Corresponding author: Muhammad Yar Khan (e-mail: muhammadyar@ciitwah.edu.pk). 
Secondly, although the reliable items of measures are adopted/adapted from various sources but the studies are conducted in dissimilar situations. In such circumstances, it becomes imperious to establish the validity and reliability. This study has comprehensively done various statistical calculations in order to establish the validity and reliability in Pakistani consumer market. This research now offers, a valid and reliable instrument for Pakistani as well as global researchers who are enthusiastic to probe into the product quality perceptions formed via food packaging cues.

\subsection{Managerial Implications}

The empirical analysis of the study confirms the relationship among the constructs together with the moderating effects. These relationships have been confirmed or disconfirmed statistically. From the standpoint of practitioners, this study provides a significant contribution in the form of understanding the mind set of consumers in a shopping situation. It may also assist the marketers to devise the marketing strategies to create favorable product perceptions and long term relations with the consumers. The marketers are suggested to avoid any kind of deceptive cues on product labeling. In Pakistani food market, the packaged food is witnessed to exhibit a fast growth due to drifting lifestyles. It would be advantageous for marketers to recognize this segment, along with other consumer segments that do not use packaged food products. As marketing values every step that can keep customers delighted and retained, an ability to meet consumers' aforesaid demand can put them in real advantageous position in the short as well as in the long run.

*Corresponding author: Muhammad Yar Khan (e-mail: muhammadyar@ciitwah.edu.pk). 


\section{References}

Aaker, D. A. and E. Joachimsthaler (2000). "The brand relationship spectrum: The key to the brand architecture challenge." California management review 42(4): 8.

Abdul Latiff, Z., Z. Mohamed, G. Rezai and N. Kamaruzzaman (2013). "The impact of food labeling on purchasing behavior among non-Muslim consumers in Klang Valley." Australian Journal of Basic and Applied Sciences 7(1): 124-128.

Ajzen, I. (1991). "The theory of planned behavior." Organizational behavior and human decision processes 50(2): 179-211.

Alba, J. W. and J. W. Hutchinson (2000). "Knowledge calibration: What consumers know and what they think they know." Journal of consumer research 27(2): 123-156.

Andéhn, M. and P. L'Espoir Decosta (2016). "The variable nature of country-to-brand association and its impact on the strength of the country-of-origin effect." International Marketing Review 33(6): 851-866.

Babcanová, D., V. Prajová and P. Marková (2012). Brand Management-the Part of Integrated Marketing Communication of Industrial Enterprises. Proceedings of the European Conference on Management, Leadership and Governance, Neapolis University Pafos.

Barclay, D., C. Higgins and R. Thompson (1995). The Partial Least Squares (pls) Approach to Casual Modeling: Personal Computer Adoption Ans Use as an Illustration.

Baron, R. M. and D. A. Kenny (1986). "The moderator-mediator variable distinction in social psychological research: Conceptual, strategic, and statistical considerations." Journal of personality and social psychology 51(6): 1173.

Bauer, M. A., J. E. Wilkie, J. K. Kim and G. V. Bodenhausen (2012). "Cuing consumerism: Situational materialism undermines personal and social well-being." Psychological Science 23(5): 517-523.

Bolton, L. E., H. T. Keh and J. W. Alba (2010). "How do price fairness perceptions differ across culture?" Journal of Marketing Research 47(3): 564-576.

Brown, J. D. (1983). "A closer look at cloze: Validity and reliability." Issues in language testing research: 237-250.

Chadwick, S. and M. Holt (2015). Utlising Latent Brand Equity as a Foundation for Building Global Sports Brands. Proceedings of the 2007 Academy of Marketing Science (AMS) Annual Conference, Springer.

Charlebois, S., A. Schwab, R. Henn and C. W. Huck (2016). "Food fraud: An exploratory study for measuring consumer perception towards mislabeled food products and influence on self-authentication intentions." Trends in Food Science \& Technology 50: 211-218.

*Corresponding author: Muhammad Yar Khan (e-mail: muhammadyar@ciitwah.edu.pk). 
Chaudhary, S. (2014). "The Role of Packaging in Consumer's Perception of Product Quality." International Journal of Management and Social Sciences Research 3(3): 17-21.

Chiuve, S. E., T. T. Fung, K. M. Rexrode, D. Spiegelman, J. E. Manson, M. J. Stampfer and C. M. Albert (2011). "Adherence to a low-risk, healthy lifestyle and risk of sudden cardiac death among women." Jama 306(1): 62-69.

Choi, J. and A. Choi (2016). "Perceptions of food labelling about allergens in food products in South Korea." British Food Journal 118(12): 2842-2854.

Chovanová, H. H., A. I. Korshunov and D. Babčanová (2015). "Impact of Brand on Consumer Behavior." Procedia Economics and Finance 34: 615-621.

Cochrane, C. J. and K. P. Ebmeier (2013). "Diffusion tensor imaging in parkinsonian syndromes A systematic review and meta-analysis." Neurology 80(9): 857-864.

Dawar, N. and P. Parker (1994). "Marketing universals: Consumers' use of brand name, price, physical appearance, and retailer reputation as signals of product quality." The Journal of Marketing: 81-95.

De Blok, B. M., B. J. Vlieg, J. Oude Elberink, E. J. Duiverman, A. DunnGalvin, J. B. Hourihane, J. R. Cornelisse-Vermaat, L. Frewer, C. Mills and A. E. Dubois (2007). "A framework for measuring the social impact of food allergy across Europe: a EuroPrevall state of the art paper." Allergy 62(7): 733-737.

De Winter, J. C. and D. Dodou (2010). "Five-point Likert items: t test versus Mann-WhitneyWilcoxon." Practical Assessment, Research \& Evaluation 15(11): 2.

Denscombe, M. (1998). The good research guide for small-scale social science projects, Buckingham: Open University Press.

Diamantopoulos, A. and K. P. Zeugner-Roth (2010). "“Country of Origin" as Brand Element." Wiley international encyclopedia of marketing.

Doss, F. and T. Robinson (2013). "Luxury perceptions: luxury brand vs counterfeit for young US female consumers." Journal of Fashion Marketing and Management: An International Journal 17(4): 424-439.

Draper, A. K., A. J. Adamson, S. Clegg, S. Malam, M. Rigg and S. Duncan (2011). "Front-of-pack nutrition labelling: are multiple formats a problem for consumers?" The European Journal of Public Health 23(3): 517-521.

Ergin, E. A. and H. Ö. Akbay (2014). Factors influencing young consumers' preferences of domestic and international fast food brands. Internation marketing trends Conference.

Fassnacht, M., P. N. Kluge and H. Mohr (2012). Do luxury pricing decisions create price continuity? Identitätsbasierte Luxusmarkenführung, Springer: 121-137.

Flach, L. (2016). "Quality upgrading and price heterogeneity: Evidence from Brazilian exporters." Journal of International Economics 102: 282-290.

Forza, C. (2010). Surveys. Researching operations management, Routledge: 98-175.

Fox, M., J. Voordouw, M. Mugford, J. Cornelisse, G. Antonides and L. Frewer (2009). "Social and economic costs of food allergies in Europe: development of a questionnaire to measure costs and health utility." Health services research 44(5p1): 1662-1678.

*Corresponding author: Muhammad Yar Khan (e-mail: muhammadyar@ciitwah.edu.pk). 
Fulgoni, V. L., D. R. Keast and A. Drewnowski (2009). "Development and validation of the nutrient-rich foods index: a tool to measure nutritional quality of foods." The Journal of nutrition 139(8): 1549-1554.

Ghani, U. and Y. Kamal (2010). "The impact of in-store stimuli on the impulse purchase behaviour of consumers in Pakistan." Interdisciplinary Journal of Contemporary Research in Business 2(8): 155-162.

Ghasemi, M., I. Matta and F. Esposito (2016). The effect of competition among brokers on the quality and price of differentiated internet services, Computer Science Department, Boston University.

Grewal, D., K. L. Ailawadi, D. Gauri, K. Hall, P. Kopalle and J. R. Robertson (2011). "Innovations in retail pricing and promotions." Journal of Retailing 87: S43-S52.

Grunert, K. G., L. Bredahl and K. Brunsø (2004). "Consumer perception of meat quality and implications for product development in the meat sector-a review." Meat science 66(2): 259-272.

Hair, J. F., C. M. Ringle and M. Sarstedt (2011). "PLS-SEM: Indeed a silver bullet." Journal of Marketing theory and Practice 19(2): 139-152.

Hair, J. F., C. M. Ringle and M. Sarstedt (2013). "Partial least squares structural equation modeling: Rigorous applications, better results and higher acceptance."

HATCH, K. L. and J. A. ROBERTS (1985). "Use of intrinsic and extrinsic cues to assess textile product quality." International Journal of Consumer Studies 9(4): 341-357.

Henseler, J., C. M. Ringle and R. R. Sinkovics (2009). The use of partial least squares path modeling in international marketing. New challenges to international marketing, Emerald Group Publishing Limited: 277-319.

Herz, M. and A. Diamantopoulos (2017). "I Use It but Will Tell You That I Don't: Consumers' Country-of-Origin Cue Usage Denial." Journal of International Marketing 25(2): 52-71.

Holt, D. B. (2002). "Why do brands cause trouble? A dialectical theory of consumer culture and branding." Journal of consumer research 29(1): 70-90.

Homburg, C., N. Koschate and W. D. Hoyer (2005). "Do satisfied customers really pay more? A study of the relationship between customer satisfaction and willingness to pay." Journal of Marketing 69(2): 84-96.

Honea, H. and S. Horsky (2012). "The power of plain: Intensifying product experience with neutral aesthetic context." Marketing Letters 23(1): 223-235.

Hsieh, M.-H. (2004). "An investigation of country-of-origin effect using correspondence analysis: a cross-national context." International Journal of Market Research 46(3): 267-296.

Huang, A., J. Dawes, L. Lockshin and L. Greenacre (2017). "Consumer response to price changes in higher-priced brands." Journal of Retailing and Consumer Services 39: 1-10.

Insch, G. S. and J. B. McBride (2004). "The impact of country-of-origin cues on consumer perceptions of product quality: A binational test of the decomposed country-of-origin construct." Journal of Business Research 57(3): 256-265.

*Corresponding author: Muhammad Yar Khan (e-mail: muhammadyar@ciitwah.edu.pk). 
Ismail, Z., S. Masood and Z. M. Tawab (2012). Factors affecting consumer preference of international brands over local brands. 2nd International Conference on Social Science and Humanity.

Jhang, J. H., S. J. Grant and M. C. Campbell (2012). "Get it? Got it. Good! Enhancing new product acceptance by facilitating resolution of extreme incongruity." Journal of Marketing Research 49(2): 247-259.

Kaiser, H. F. (1974). "An index of factorial simplicity." Psychometrika 39(1): 31-36.

Kalicharan, H. D. (2014). "The Effect And Influence Of Country-Of-Origin On Consumers' Perception Of Product Quality And Purchasing Intentions." The International Business \& Economics Research Journal (Online) 13(5): 897.

Kapferer, J.-N. (2012). "Abundant rarity: The key to luxury growth." Business Horizons 55(5): 453-462.

Kardes, F. R., J. Kim and J.-S. Lim (2001). "Consumer expertise and the perceived diagnosticity of inference." Advances in Consumer Research 19(1): 409-410.

Kelley, K., J. Hyde and J. Bruwer (2015). "US wine consumer preferences for bottle characteristics, back label extrinsic cues and wine composition: A conjoint analysis." Asia Pacific Journal of Marketing and Logistics 27(4): 516-534.

Khan, H. and D. Bamber (2008). "Country of origin effects, brand image, and social status in an emerging market." Human Factors and Ergonomics in Manufacturing \& Service Industries 18(5): 580-588.

Kim, J., B. Jin and J. L. Swinney (2009). "The role of etail quality, e-satisfaction and e-trust in online loyalty development process." Journal of retailing and Consumer services 16(4): 239-247.

Kim, R. (2008). "Japanese consumers' use of extrinsic and intrinsic cues to mitigate risky food choices." International Journal of Consumer Studies 32(1): 49-58.

Kluge, P. and M. Fassnacht (2014). Selling luxury goods online? Effects of making the inaccessible accessible. 2014 Monaco Symposium on Luxury.

Kostyra, D. S., J. Reiner, M. Natter and D. Klapper (2016). "Decomposing the effects of online customer reviews on brand, price, and product attributes." International Journal of Research in Marketing 33(1): 11-26.

Krejcie, R. V. and D. W. Morgan (1970). "Determining sample size for research activities." Educational and psychological measurement 30(3): 607-610.

Kupiec, B. and B. Revell (2001). "Measuring consumer quality judgements." British Food Journal 103(1): 7-22.

Lähteenmäki, L., P. Lampila, K. Grunert, Y. Boztug, Ø. Ueland, A. Åström and E. Martinsdóttir (2010). "Impact of health-related claims on the perception of other product attributes." Food Policy 35(3): 230-239.

Lee, J. K., B.-K. Lee and W.-N. Lee (2013). "Country-of-origin fit's effect on consumer product evaluation in cross-border strategic brand alliance." Journal of Business Research 66(3): $354-363$.

*Corresponding author: Muhammad Yar Khan (e-mail: muhammadyar@ciitwah.edu.pk). 
Lewis, K. E., C. Grebitus and R. M. Nayga (2016). "The impact of brand and attention on consumers' willingness to pay: Evidence from an eye tracking experiment." Canadian Journal of Agricultural Economics/Revue canadienne d'agroeconomie 64(4): 753-777.

Lindley, P. and S. N. Walker (1993). "Theoretical and methodological differentiation of moderation and mediation." Nursing Research 42(5): 276-279.

Loken, B., R. Ahluwalia and M. J. Houston (2010). Brands and Brand Management, New york: Psychology Press.

Machiels, C. J. and N. Karnal (2016). "See how tasty it is? Effects of symbolic cues on product evaluation and taste." Food quality and preference 52: 195-202.

Main, J. (1994). "Quality wars." New York: Free Press McDougall, Gordon HG and Terrence Levesque (2000)." customer satisfaction with service: putting perceived value into the Equation" journal of service marketing 14(5): 392-410.

Malhotra, Y. and D. F. Galletta (1999). Extending the technology acceptance model to account for social influence: Theoretical bases and empirical validation. Systems sciences, 1999. HICSS-32. Proceedings of the 32nd annual Hawaii international conference on, IEEE.

Mascarello, G., A. Pinto, N. Parise, S. Crovato and L. Ravarotto (2015). "The perception of food quality. Profiling Italian consumers." Appetite 89: 175-182.

Matell, M. S. and J. Jacoby (1971). "Is there an optimal number of alternatives for Likert scale items? Study I: Reliability and validity." Educational and psychological measurement 31(3): 657-674.

Mathe-Soulek, K., M. Krawczyk, R. J. Harrington and M. Ottenbacher (2016). "The impact of price-based and new product promotions on fast food restaurant sales and stock prices." Journal of food products marketing 22(1): 100-117.

Maynes, E. S. (1976). Decision-making for consumers: An introduction to consumer economics, Prentice Hall.

Mishra, S., S. N. Singh, X. Fang and B. Yin (2017). "Impact of diversity, quality and number of brand alliance partners on the perceived quality of a new brand." Journal of Product \& Brand Management 26(2): 159-176.

Miyazaki, A. D., D. Grewal and R. C. Goodstein (2005). "The effect of multiple extrinsic cues on quality perceptions: A matter of consistency." Journal of consumer research 32(1): 146153.

Mørkbak, M. R., T. Christensen and D. Gyrd-Hansen (2010). "Choke price bias in choice experiments." Environmental and resource economics 45(4): 537-551.

Moslehpour, M. and N. T. Le Huyen (2014). "The influence of perceived brand quality and perceived brand prestige on purchase likelihood of iPhone and HTC mobile phone in Taiwan." Research in Business and Management 1(1): 62-77.

Mugge, R. and J. P. Schoormans (2012). "Newer is better! The influence of a novel appearance on the perceived performance quality of products." Journal of Engineering Design 23(6): 469484.

*Corresponding author: Muhammad Yar Khan (e-mail: muhammadyar@ciitwah.edu.pk). 
Nath Sanyal, S. and S. K. Datta (2011). "The effect of perceived quality on brand equity: an empirical study on generic drugs." Asia Pacific Journal of Marketing and Logistics 23(5): 604-625.

Pappu, R., P. G. Quester and R. W. Cooksey (2005). "Consumer-based brand equity: improving the measurement-empirical evidence." Journal of Product \& Brand Management 14(3): 143-154.

Parguel, B., T. Delécolle and P. Valette-Florence (2016). "How price display influences consumer luxury perceptions." Journal of Business Research 69(1): 341-348.

Pearce, P. L. (2016). "Trends in Consumer Behaviour." Entrepreneurship und Tourismus: Unternehmerisches Denken und Erfolgskonzepte aus der Praxis: 2251.

Pedersen, P. B., W. J. Lonner, J. G. Draguns, J. E. Trimble and M. R. Scharron-del Rio (2015). Counseling across cultures, Sage Publications.

Priilaid, D., G. Human, K. Pitcher, T. Smith and C. Varkel (2017). "Are consumers' quality perceptions influenced by brand familiarity, brand exposure and brand knowledge? Results from a wine tasting experiment." South African Journal of Business Management 48(2): 45-54.

Qasem, A., R. Baharun and A. Yassin (2016). "The Role of Extrinsic Product Cues in Consumers' Preferences and Purchase Intentions: Mediating and Moderating Effects." TEM Journal 5(1): 85 .

Rahman, O., B. C. Fung, Z. Chen and X. Gao (2017). "A cross-national study of apparel consumer preferences and the role of product-evaluative cues." Asia Pacific Journal of Marketing and Logistics 29(4): 796-812.

Randhawa, P., A. H. Kirca, M. B. Talay and M. B. Akdeniz (2017). Interactive Effects of Product and Brand Portfolios on Firm Value. Creating Marketing Magic and Innovative Future Marketing Trends, Springer: 95-98.

Rao, A. R. and K. B. Monroe (1988). "The moderating effect of prior knowledge on cue utilization in product evaluations." Journal of consumer research 15(2): 253-264.

Ravikanth, M. and P. V. Rao (2016). "Buying Behavior of Electronic Products in Andhra PradeshA Study of Selected Electronic Consumer Product."

Rezvani, S., G. J. Dehkordi, M. S. Rahman, F. Fouladivanda, M. Habibi and S. Eghtebasi (2012). "A conceptual study on the country of origin effect on consumer purchase intention." Asian Social Science 8(12): 205.

Riley, F. D. O., W. Lomax and A. Blunden (2004). "Dove vs. Dior: Extending the brand extension decision-making process from mass to luxury." Australasian Marketing Journal (AMJ) 12(3): 40-55.

Roselli, L., D. Carlucci, O. J. Rover and B. De Gennaro (2018). "The Effects of Extrinsic Cues on Olive Oil Price in Brazil." Journal of International Food \& Agribusiness Marketing 30(1): 70-87.

Rungtrakulchai, R. (2018). "The relationship between price deals, perceived quality, and brand equity for a high involvement product." AU Journal of Management 11(2): 36-45.

*Corresponding author: Muhammad Yar Khan (e-mail: muhammadyar@ciitwah.edu.pk). 
Saeed, M. N. R. M. K. and A. Aslam (2015). "Consumer's Brand Purchase Intention in Emerging Markets Like Pakistan." J. Marketing Consum. Res 15: 1-9.

Sharma, K. and S. Garg (2016). "An Investigation into Consumer Search and Evaluation Behaviour: Effect of Brand Name and Price Perceptions." Vision 20(1): 24-36.

Shehzad, U., S. Ahmad, K. Iqbal, M. Nawaz and S. Usman (2014). "Influence of Brand Name on consumen Choise and Decision." IOSR Journal of Business and Management (IOSR-JBM) e-ISSN: $72-76$.

Spence, C. and C. Velasco (2018). "On the multiple effects of packaging colour on consumer behaviour and product experience in the 'food and beverage'and 'home and personal care'categories." Food Quality and Preference.

ST Wang, E. (2013). "The influence of visual packaging design on perceived food product quality, value, and brand preference." International Journal of Retail \& Distribution Management 41(10): 805-816.

Sudman, S. (1980). "Improving the quality of shopping center sampling." Journal of Marketing research: 423-431.

Thøgersen, J., S. Pedersen, M. Paternoga, E. Schwendel and J. Aschemann-Witzel (2017). "How important is country-of-origin for organic food consumers? A review of the literature and suggestions for future research." British Food Journal 119(3): 542-557.

Tiozzo, B., S. Mari, M. Ruzza, S. Crovato and L. Ravarotto (2017). "Consumers' perceptions of food risks: A snapshot of the Italian Triveneto area." Appetite 111: 105-115.

Truong, Y., R. McColl and P. J. Kitchen (2009). "New luxury brand positioning and the emergence of masstige brands." Journal of Brand Management 16(5-6): 375-382.

Türkekul, B., C. Günden, C. Abay and B. Miran (2010). "The competitiveness of Turkish olive oil on the world market." Journal of Food, Agriculture \& Environment 8(2): 68-73.

Turnbull, J., H. Adams and D. Gorard (2015). "The diagnosis and management of food allergy and food intolerances." Alimentary pharmacology \& therapeutics 41(1): 3-25.

Uma, S. and B. Roger (2003). "Research methods for business: A skill building approach." book.

Veale, R. (2008). "Sensing or knowing? Investigating the influence of knowledge and selfconfidence on consumer beliefs regarding the effect of extrinsic cues on wine quality." International Journal of Wine Business Research 20(4): 352-366.

Veale, R. and P. Quester (2009). "Do consumer expectations match experience? Predicting the influence of price and country of origin on perceptions of product quality." International business review 18(2): 134-144.

Velčovská, Š. and D. Hadro (2018). "Generation Y Perceptions and Expectations of Food Quality Labels in the Czech Republic and Poland." Acta Universitatis Agriculturae et Silviculturae Mendelianae Brunensis 66(1): 325-334.

Voordouw, J., J. R. Cornelisse-Vermaat, S. Pfaff, G. Antonides, D. Niemietz, M. Linardakis, O. Kehagia and L. J. Frewer (2011). "Preferred information strategies for food allergic consumers. A study in Germany, Greece, and The Netherlands." Food quality and preference 22(4): 384-390.

*Corresponding author: Muhammad Yar Khan (e-mail: muhammadyar@ciitwah.edu.pk). 
Wansink, B. (2004). "How do front and back package labels influence beliefs about health claims?" Family Economics and Nutrition Review 16(1): 61-62.

Weisstein, F. L., K. B. Monroe and M. Kukar-Kinney (2013). "Effects of price framing on consumers' perceptions of online dynamic pricing practices." Journal of the Academy of Marketing Science 41(5): 501-514.

Wigley, S. and C.-L. Rachel Chiang (2009). "Retail internationalisation in practice: per una in the UK and Taiwan." International Journal of Retail \& Distribution Management 37(3): 250270.

Wills, J. M., D. B. Schmidt, F. Pillo-Blocka and G. Cairns (2009). "Exploring global consumer attitudes toward nutrition information on food labels." Nutrition Reviews 67(suppl_1): S102-S106.

Zafar, M. Z., N. A. Hashim and F. b. Halim (2017). "The Pivotal Role of User-Friendly Food Label and Personality Traits on Intention to Consume Packaged Food Products." Journal of Food Products Marketing 23(7): 835-856.

Zeb, H., K. Rashid and M. B. Javeed (2011). "Influence of Brands on Female Consumer's Buying Behavior in Pakistan." International Journal of Trade, Economics and Finance 2(3): 225.

Zeithaml, V. A. (1988). "Consumer perceptions of price, quality, and value: a means-end model and synthesis of evidence." The Journal of marketing: 2-22.

Zurzolo, G. A., J. J. Koplin, M. L. Mathai, M. K. Tang and K. J. Allen (2013). "Perceptions of precautionary labelling among parents of children with food allergy and anaphylaxis." The Medical Journal of Australia 198(11): 621-623.

*Corresponding author: Muhammad Yar Khan (e-mail: muhammadyar@ciitwah.edu.pk). 
MUHAMMAD YAR KHAN has a Ph.D. in accounting and finance from Adam Smith Business School, University of Glasgow (triple accredited university) UK funded by Commonwealth Scholarship Commission. He have done Master of Science in Finance under a split program funded by ERASMUS MUNDUS Europe from Sanio University Benevento, Italy and MAJU Pakistan. He have another Master in Business Administration from International Islamic University and awarded with Distinction certificate. He has extensive experience of 11 years in the field of research and academic. During his Ph.D. studies, he worked as Graduate Teaching Assistant and won 'Teaching Excellence Award' from the world diverse class in Adam Smith Business School. Currently, he is working as Assistant Professor at COMSATS University Islamabad, Wah Campus. His research areas are Corporate Governance, Corporate Finance, Islamic Finance, Islamic Banking and Portfolio Management. He also work in multidisciplinary areas and publishing in national international journals.

ANAM JAVEED has a Ph.D. in marketing school of business management, University Utara Malaysia. She has done her masters in marketing from Federal Urdu University of Science, Arts and Technology Islamabad. She has done her BBA (hons) in marketing from COMSATS Institute of IT Wah Campus. Currently she is working as an Assistant Professor of marketing in University of Wah. Her research areas are Political marketing, consumer behavior, Islamic marketing and various other areas of marketing.

ASIF KHURSHID MIAN holds PhD from International Islamic University, Malaysia. He carry seventeen years of professional and academic experience in the domains of Marketing, Brand management, Consumer Behavior and Product development. Currently leading and supervising multiple Doctoral candidates towards the degree and research completion. He is teaching multiple courses both at graduate and post graduate level. He is working on multiple publications in collaboration with other scholars across the globe; both in guidance and contributory capacities.

Uzma Noor holds Ph D. in Marketing. She is working as a Lecturer of Marketing in International Islamic University, Islamabad, Pakistan. She has published several research articles in national and internal journals. Her areas of research are social media marketing, consumer behaviour and advertising. She can be contacted at uzma.amer@iiu.edu.pk

*Corresponding author: Muhammad Yar Khan (e-mail: muhammadyar@ciitwah.edu.pk). 